\title{
A PRESENÇA DE MULHERES NA EDUCAÇÃO ANGOLANA
}

\author{
Ruth Canga Buza Ferreiral \\ Terezinha Valim Oliver Gonçalves²
}

\begin{abstract}
RESUMO
Esta é uma pesquisa narrativa que trata da presença das mulheres no sistema educacional angolano. Por meio de fotos e relatos, traçamos o processo de ingresso das mulheres na educação angolana. Os relatos foram obtidos por meio de entrevista semiestruturada realizada com professoras em Angola. Para este espaço, trazemos a história de duas professoras, denominadas de Nsona e Tchissola (nomes fictícios), que possuem formação de nível superior. A professora Nsona leciona no ensino superior e a professora Tchissola na educação básica. A escolha de ambas foi realizada em razão da vivência dessas mulheres na educação, do período final da colonização no país ao período de guerra civil. O objetivo desta pesquisa é conhecer a trajetória de formação dessas mulheres no contexto angolano, adentrando na história do país e compreendendo os impactos dessa história na formação das professoras. As trajetórias de vida de Nsona e Tchissola, agora conhecidas e podem vir a ser fonte de inspiração e reformulação do sistema educacional angolano, abrindo mais espaço de profissão para as mulheres e sua valorização.
\end{abstract}

Palavras-chave: Pesquisa narrativa. História de vida. Educação. Mulher angolana.

\section{THE PRESENCE OF WOMAN IN ANGOLAN EDUCATION}

\begin{abstract}
This narrative research concerns the presence of women in the Angolan educational system. By means of photographs and accounts, the process of the women entering the Angolan education was traced. The accounts were obtained through semistructured interviews carried out in Angola with two teachers, for this paper, entitled Nsona and Tchissola (fictitious names), who possess higher level education. Professor Nsona lectures in university education and Teacher Tchissola in elementary education. Both women chose their profession according to their experience in education, in the final period of colonization of the country at the time of the civil war. The objective of this research is to understand the path of education of these women in the Angolan context, exploring the country's history and understanding the impacts of this story in the qualification of these teachers. Enabling the life story of Nsona and Tchissola to be known and used as a source of inspiration and rearrangement of the Angolan educational system, can open up more space for women's careers and their valuation.
\end{abstract}

Keywords: Narrative inquiry. Life story. Education. Angolan woman.

\footnotetext{
1 Doutora em Educação em Ciências pelo Instituto de Educação Matemática e Científica da UFPA. Pesquisadora narrativa. Licenciada em Ciências Naturais com Habilitação em Química pela UEPAORCID: https://orcid.org/0000-0001-8572-4742. . E-mail: ruthbuza@hotmail.com

2 Doutora em Educação pela UNICAMP. Pesquisadora Narrativa. Licenciada em Ciências Biológicas e História Natural pela UFRGS. Docente do Instituto de Educação Matemática e Científica da UFPA. ORCID: http://orcid.org/0000-0001-8285-3274. E-mail: tvalim@ufpa.br
} 


\section{LA PRESENCIA DE LAS MUJERES EN LA EDUCACIÓN ANGOLEÑA}

\section{RESUMEN}

Esta investigación narrativa acerca se dela presencia de mujeres en el Sistema educativo angoleño. A través de fotos e informes, restreamos el proceso de ingresar a las mujeres en la educación angoleña. Los informes se obtuvieron a través de una entrevista semiestructurada realizada en Angola con dos maestros, llamados Nsona y Tchissola (nombresficticios), los maestros tienen educación superior. La profesora Nsona enseña en educación superior y la professora Tchissola en educación básica. La elección de ambos se hizoen vista de la experiencia de estar mujeres em educación, desde el período final de colonización en el país hasta el período de Guerra civil. El objetivo de esta investigación es conocer la trayectoria de capacitación de estar mujeres en el context angoleño, ingresar a la historia del país y comprenderlos impactos de esta historia en la capacitación de docents. Permitir que la trayetorias de vida de Nsona y Tchissola sean conocidas e sirvan como fuente de inspiración y reformulación del Sistema educativo angoleño, abriendo más espacio para las mujeres y sy valorización.

Palabras clave: Investigación narrativa. História de vida. Educación. Mujer angoleña.

\section{INTRODUÇÃO}

Esta é uma pesquisa qualitativa, de abordagem narrativa, cujos fundamentos teóricos situam-se em Connelly e Clandinin (1995) e Clandinin e Connelly (2011) e que tem como foco central investigativo a experiência humana. Neste espaço, apresentamos um recorte de uma pesquisa mais ampla, tema de tese ${ }^{3}$ de doutorado da primeira autora, sob orientação da coautora. Para a análise dos dados construídos, assumimos a análise textual discursiva (ATD), tendo como base teórica Moraes e Galiazzi (2006). Tivemos o objetivo de pesquisar histórias de formação docente em Angola, buscando relatos que expressassem 0 modo como os formadores investigados se constituíram e como tais histórias contribuem para a formação de professores de Ciências no país. Evidenciamos desafios, aventuras e desventuras, bem como superações pessoais e profissionais durante o percurso formativo que, de algum modo reverberam em sua prática docente.

\footnotetext{
3 Histórias de vida de formadores de professores de Ciências em Angola. Ruth Canga Buza Ferreira, sob orientação de Terezinha Valim Oliver Gonçalves, defendida em 2018, no Instituto de Educação Matemática e Científica da UFPA.
} 
O contexto investigativo é Angola, que passou por longo período colonial e de escravidão e logo após sua independência, por uma guerra civil. Destacamos a importância de apresentarmos com clareza o contexto, baseado na afirmação de Gonçalves (2000, p. 44):

O cenário é o lugar onde a história ocorre ou ocorreu, onde os personagens que agora contam uma história a viveram. É o lugar que tem um contexto social e cultural próprio que contribuiu de algum modo para aquela história ocorrer. Descrevê-lo numa narrativa, tanto em termos físicos, como dos personagens, contribui em muito para a qualidade de uma pesquisa narrativa.

Por partilharmos da mesma compreensão da importância do cenário na escrita narrativa, é que, olhamos para esse contexto, com auxílio de duas professoras angolanas, que contribuem para que respondamos à seguinte pergunta de pesquisa: Como se caracterizam os processos de formação de professoras angolanas e o contexto educacional em que vivem?

Para construir respostas à pergunta investigativa, valemo-nos de depoimentos das professoras e de informações históricas sobre o país e sua educação, caracterizando-se, pois, os textos de campo como documentação oficial e informações não oficiais, ou seja, advindas por quem viveu parte da história do país, neste caso, as professoras colaboradoras.

Organizamos este artigo com uma breve introdução, caracterizando a pesquisa qualitativa realizada, apresentação resumida do contexto histórico sobre Angola, uma discussão sobre o papel das mulheres na sociedade angolana, as histórias de vida e superação de duas professoras que falam de si e de sua formação e profissionalização como docentes, em íntima discussão com o contexto social e, por fim, apresentamos as considerações finais, com conclusões e recomendações.

A seguir, apresentamos um breve contexto histórico de Angola.

\section{UMA BREVE CONTEXTUALIZAÇÃO DA PESQUISA}

Antes de adentrarmos à discussão sobre a educação angolana, para discutirmos o percurso de inserção das mulheres no sistema educacional, é 
necessário voltarmos ao passado para contextualizar historicamente o país do qual essas mulheres são fruto.

Anteriormente à chegada de Diogo Cão, o território hoje conhecido como Angola, era um grande emaranhado de reinos, sendo o principal o reino do Kongo. Esses reinos vinham de um mesmo tronco linguístico, denominado bantu (pessoa). Apesar de originados de um mesmo tronco linguístico, é necessário destacar que havia inúmeras diferenças entre essas populações, o que de modo algum pode ser desconsiderado. De acordo com Rendinha (2009, p. 28):

Os Bantos em geral têm sido definidos, simplificadamente, como um grupo de povos que se serve de qualquer forma de raíz ntu, para qualificar as pessoas humanas. Essa raíz, com o prefixo do plural ba, forma o conjunto ba-ntu, e daí as formas Bantu ou Banto que os designam.

Rendinha (2009, p. 29) também expressa que:

Os Bantos caracterizam-se culturalmente por uma tecnologia variada, por uma escultura de grande originalidade estilística, por um somatório de conhecimentos empíricos notáveis e por uma leitura oral, densa e interessante, de notável expressão intelectual. Os Bantos angolanos repartem conforme ficou referido em nove Grandes Grupos Etnolinguísticos, os quais, por sua vez se subdividem em cerca duma centena de subgrupos, tradicionalmente designados tribos.

Os habitantes do reino do Kongo, que posteriormente fariam parte do que hoje chamar-se-ia Angola, constitui-se um desses grupos originados dos Bantos. Vale ressaltar que, embora os subgrupos pertencentes ao tronco linguístico Banto tivessem muitas semelhanças, não poderiam ser considerados iguais.

Especificando a nossa abordagem sobre a origem das mulheres angolanas, chegamos ao reino do Kongo, que é considerado como o reino que posteriormente iria constituir a denominada Angola, sendo localizado nos atuais territórios da "República de Angola, da República do Congo e em parte da República Democrática do Congo" (CAREGNATO, 2011). De modo mais preciso, parte das Repúblicas de Angola, e Democrática do Congo, e em toda extensão das Repúblicas do Gabão, e do Congo. 
Os habitantes desse reino viviam subordinados ao ManiKongo (o rei):

A figura do rei representava, além do poder político, uma relação com as questões míticas, que explicavam a origem e organização da sociedade bantu. Suas vestimentas e os adornos eram uma constante representação de sua cosmovisão (CAREGNATO, 2011, p. 7).

A sociedade, nesse período, possuía sistema monetário embasado no uso de pequenas conchas ou, até mesmo, de tecidos. Técnicas agrícolas e materiais para o desenvolvimento da agricultura eram construídas pela própria população.

Os nzimbos eram conchas utilizadas no reino do Kongo e na região, como moedas que vinham da ilha de Luanda, e eram recolhidos por mulheres que as selecionavam e limpavam, para sua utilização. Esse "produto" era explorado como monopólio do Mani Kongo, rendendo-lhe grande valia (CAREGNATO, 2011, p. 7).

A organização político-econômica permitia que o reino tivesse um sistema social bem consolidado, chamando a atenção dos portugueses para se estabelecerem nesse lugar. Nesse reino, mulheres e homens tinham suas obrigações definidas, sendo as mulheres responsáveis pela agricultura, cuidado com as crianças e os homens responsáveis pela prática da caça. Essas atividades eram transmitidas de geração em geração, sendo reservada aos adultos a responsabilidade por tal instrução.

Diante desses fatos, podemos constatar que a sociedade conguense era bem desenvolvida dentro das possibilidades de uma sociedade que não tinha contato com outras culturas, nesse caso a europeia. Sua estrutura social fluía de acordo com a lógica julgada adequada para o seu contexto.

Foi nesse cenário que Diogo Cão, navegador português, chegou ao Kongo, em 1498. A presença portuguesa se mantém por cerca de 500 anos, no primeiro momento sendo ciceroneados pelos nativos, posteriormente criando laços de troca entre a sociedade conguense por meio de presentes e "intercâmbios" educacionais. Esse período inicial foi de extrema importância para que os portugueses pudessem fixar raízes na África.

As alternâncias de poder, vontade política, brigas familiares, sagacidade portuguesa, displicência conguense e tantos outros aspectos na 
história contribuíram para, posteriormente, o Kongo tornar-se colônia portuguesa, tendo seus filhos espalhados pelo mundo como escravos, sem perspectiva de volta.

Estudos indicam em várias áreas de conhecimento, principalmente na da Educação, Sociologia e História que, nos meados do século XVIII, foram levados da terra - mãe Angola, como escravos, cerca de 4 milhões de homens, mulheres e crianças para vários cantos do mundo, inclusive para o Brasil.

A opressão portuguesa contribuiu para o fim do reino conguense, tornando-se esse, um mero fantoche nas mãos dos colonizadores. Sua língua, organização social, produção cultural foram aos poucos sendo destruídos. Os descendentes que ali ficaram construíram suas vidas acreditando naquilo que durante séculos foi incutido na sociedade, que a cultura autóctone não era importante, que negros eram inferiores aos brancos e não mereciam ocupar os mesmos espaços dentro da sociedade.

Essa construção propiciou aos autóctones o desenvolvimento de uma mente colonizada, uma mente com aversão a sua própria cultura, em detrimento da cultura ocidental, tomando sistematicamente como base a cultural ocidental superior e, portanto, considerando-a a única possível de levar ao desenvolvimento.

O jugo português começa a ter fim por volta de 1965, graças à educação. A exigência de cursos superiores para dar continuidade aos estudos daqueles que viviam na colônia fez-se presente e, aos poucos, os movimentos de libertação foram ganhando força culminando, em 1975, com o fim da colonização, pela independência de Angola.

A independência, por sua vez, embora tenha sido necessária e celebrada por todos, não deu início a um período de paz e crescimento, pelo contrário, após a independência, a ex-colônia portuguesa se viu imersa em uma guerra civil que perdurou até o ano de 2002. Os movimentos de libertação (MPLA, FNLA e UNITA), outrora unidos no mesmo objetivo, a independência, se viram agora adversárias por divergências políticas e 
ideológicas sobre o rumo do país. É nesse contexto de instabilidade que Nsona e Tchissola, colaboradoras dessa pesquisa foram constituídas.

Nsona e Tchissola são professoras que vivenciaram os 40 anos de guerra civil em Angola, mas que ainda assim não esmoreceram e conseguiram concluir os seus estudos.

Nsona é formada em Licenciatura em Matemática, concluiu o seu doutorado em 2010 em Madrid, trabalha com formação de professores. Tchissola é formada em Licenciatura em Biologia e leciona no primeiro ciclo, na Escola Mandume $\left(7^{a}, 8^{a}\right.$ e $\left.9^{a}\right)$. Os relatos de ambas foram obtidos por meio de entrevista presencial, na qual relataram suas histórias de vida e formação em Angola.

A seguir aprofundamos discussão sobre o papel da mulher na história angolana.

\section{MAMMA ANGOLA: a mulher no contexto social}

Na sociedade matrilinear, a mulher exerce um dos mais importantes papéis na organização familiar, cuja descendência é contada a partir dessa personagem social, como ocorre no cenário angolano. Diferente do que se espera quando pensamos em sociedades antigas, a descendência das pessoas era contada a partir das mulheres. De acordo com Caregnato (2010, p. 4):

A organização familiar bantu se dava pelo sistema da matrilinearidade ou patrilinearidade, podendo haver a coexistência dos dois regimes. No sistema matrilinear, a descendência passava por meio das mulheres, aparecendo sempre um epónimo feminino, sendo que o tio materno tinha autoridade sobre os filhos das suas irmãs. Já no sistema patrilinear, o filho pertence à família do pai, reagrupando os descendentes por via masculina, de um antepassado varão, conhecido ou mítico.

O sistema matrilinear destaca a importância da mulher na sociedade bantu, e não só, mas a voz que muitos insistem em calar. As mulheres, nessa sociedade, tinham voz e poder de decisão. As mulheres tinham grande importância para a subsistência da sua comunidade por meio da agricultura. No entanto, essa função, de acordo com Caregnato (2010, p. 4), 
é associada às mulheres pela necessidade que havia de elas serem mantidas a salvo para procriação:

Historicamente, devido à necessidade contínua de manter e aumentar o número de integrantes das comunidades, as mulheres engravidavam em continuação, o que lhes dificultavam irem em busca de caça e coleta em regiões distantes, tarefa voltada aos homens. Por motivo de segurança, as cobiçadas mulheres não se afastavam igualmente das aldeias. Em função dos empecilhos, das mulheres saírem das aldeias, havia um contato íntimo entre elas e o meio ambiente, as plantas e as estações, o que acabou se revertendo no processo de início das práticas agrícolas, tendo as mulheres como protagonistas.

Assim sendo, temos um motivo para a prática agrícola ser exercida por mulheres, o que, de certa forma, amplia o papel feminino na engrenagem da manutenção da sociedade bantu. Ainda na Angola contemporânea, a agricultura familiar é dirigida majoritariamente por mulheres, o que tem levado o governo de Angola a realizar, atualmente, o Fórum da Mulher Rural, no qual a grande ênfase dos debates é a agricultura familiar.

No contexto angolano, a procriação e agricultura eram as principais funções das mulheres no período pré-colonial. Menezes (2000, p. 102) afirma que os povos de origem bantu são "hábeis, historicamente, no trabalho agrícola, conheciam o arado antes da chegada do homem branco, revelando, no século XX, aptidão também para o comércio".

Mas vale destacar que:

São as mulheres as verdadeiras agricultoras, e as grandes experientes das técnicas agrícolas. A organização da produção agrícola nas sociedades rurais de caçadores-agricultores, coloca o chefe da família poligínica na situação de gerente de pequena empresa agrícola familiar, onde as esposas do marido comum constituem a mão de obra. São os operários agrícolas e, de certo modo, o seu capital-trabalho, em termos regulados pelo costume e de perfeita intercompreensão, havendo a notar que o status social destas mulheres é notavelmente elevado, mercê da sua importante ação econômica (RENDINHA, 2009, p. 81).

Assim sendo, podemos concluir que as mulheres são parte fundamental na sociedade africana, exercendo papel importante no que tange ao sustento familiar e à expansão da comunidade.

No entanto, isso não significa reconhecimento ou obtenção das mesmas vantagens outorgadas aos homens. Na trajetória milenar do povo 
bantu, são poucas as mulheres que tiveram notória visibilidade. A mais conhecida nesse contexto foi Nzinga Mbandi que, mesmo não tendo fixado um regime político em larga escala, é descrita como mulher com grande poder bélico e de liderança, contribuindo com/para a resistência ante a dominação colonial. Filha de um rei e de uma escrava, se fez conhecida por meio de infindáveis visões estratégicas. De acordo com Weber (2000, p. 99):

Após cinco anos governando o Ndongo, refugia-se em Matamba, reino com tradição em governos femininos. Esse fator torna sua estada no poder com possibilidades maiores de permanência. Apesar do pouco tempo no poder no reino do Ndongo, seus empreendimentos bélicos já são suficientes para sua figura ficar afamada. Em Matamba, a rainha dirigia sempre os exércitos contra os portugueses, situação que também contribuiu para a produção em torno da rainha de conceitos que a distinguiam das demais rainhas de Matamba.

A figura de Nzinga reforça mais uma vez o poder feminino no que tange à capacidade de exercer funções cuja sociedade julga serem próprias apenas dos homens, e reforça, também, a necessidade da presença feminina para a construção de uma trajetória eficaz na sociedade angolana. No entanto, embora seja ela um símbolo nacional, Weber (2011, p. 105) chama atenção de que:

Seus escritos são insuficientes para afirmarmos que Nzinga, enquanto mulher, foi uma exceção no poder, ou que uma figura feminina governando era algo comum. Essa questão é demasiada polêmica e rodeia todos os estudos acerca de Nzinga Mbandi. Sabe-se que as fontes ainda não se esgotaram e que um estudo específico é necessário. Como esse estudo carece, esta questão divide pesquisadores. O que por ora pode-se constatar é que Nzinga Mbandi governou e guerreou de forma aguerrida e determinada, causando estranhamento e deslumbramento aos que a conheciam e a descreviam.

De acordo com Fonseca (2014, p. 4) "no contexto das invasões lusitanas, Nzinga aparecia como a melhor alternativa para proteger a população e salvaguardar o reino, pois vinha acompanhada de bem treinados guerreiros jagas". Nzinga foi a prova viva em um período de intensos conflitos que as mulheres poderiam ocupar os mesmos níveis de liderança masculina. O reino da Matamba, por exemplo para onde Nzinga 
migrou e obteve espaço maior como líder, era conhecido por ser um reino de mulheres guerreiras. De acordo com Fonseca $(2014$, p. 8):

\begin{abstract}
Nas genealogias registradas pelas tradições orais, as mulheres aparecem com frequência assumindo governos e posições centrais na África Central. Mas comandar tropas e manejar armas eram tarefas exclusivas de homens? As mulheres jagas sempre acompanhavam os deslocamentos dos kilombos, mas permaneciam no acampamento preparando os alimentos ou fazendo alguma tarefa logística enquanto os homens batalhavam. Sem dúvida, Nzinga transpôs este papel que as mulheres tinham no interior do kilombo, pois comandou seu exército pessoalmente, era uma excelente lutadora, tinha força física, agilidade e sabia manusear muito bem as armas.
\end{abstract}

Outras mulheres também se destacam nesta época: Kimpa Vita, uma sacerdotiza profetisa, a Rainha LuejyA'Konde, dentre outras. O que podemos inferir é que houve uma presença feminina na história angolana que contribuiu para a constituição histórica da sociedade. E o mais importante, não se tratava de uma presença pacífica aos desmandos dos colonizadores, mas sim uma presença forte e de liderança consistente.

As mulheres foram personagens sociais importantes para manutenção das comunidades no que tange ao sustento, foram importantes na resistência aos desmandos do colonizador e, anos mais tarde, mantém-se importantes e cruciais no período da guerra civil, visto que muitas foram as estratégias assumidas para evitar que crianças fossem retiradas de si para lutarem na guerra, conforme relata Pontes (2005, p. 18, apud DIAS, 2011, p.8):

Antigamente, os homens todos iam para a guerra, os meninos eram retirados à força de casa. Mas eu fui esperta com meus filhos: desde pequenos, sempre os levava no médico. Queixava-me de uma dor no peito, uma vista que enxerga mal, uma perna que dói, de uma saúde que era fraca. Pegava as receitas e guardava todas, mas não dava os remédios, eles sempre tiveram saúde. Com aquelas receitas, enganava o exército, pensava que meus filhos tinham saúde fraca. Por isso, nunca foram chamados.

Registros assim reiteram a importância da mulher no contexto da guerra, mas, ainda assim, não são levados em consideração para que elas ocupem o lugar de destaque que merecem dentro da sociedade.

Durante o processo de diálogo frente à eminência da independência, não se viu uma abertura substancial das mulheres em relação às discussões 
que consolidaram a independência. Ainda nesse mesmo contexto conturbado, o país estava em constantes conflitos e, assim, a sociedade movia-se sem leis, fazendo com que, dessa forma, muitas mulheres sofressem abusos, tanto de civis, quanto de militares. De acordo com Dias (201 1, p. 90):

Jovens e adultas eram molestadas de diferentes maneiras por aqueles que detinham alguma forma de poder sobre elas, como os militares e os guerrilheiros, que aproveitavam o caos da guerra e a autoridade que tinham nesse cenário para violar as mulheres, que não teriam a quem recorrer [...] A ideia da vulnerabilidade da mulher angolana à violência sexual estava tão presente na sociedade que até então todas as pessoas próximas das meninas (tio, pai, madre, padres católicos) tinham certeza do que aconteceria caso elas fossem capturadas pelas tropas. Para evitar tal violência, os envolvidos se empenharam em mantê-las distantes do ímpeto dos soldados que as procuravam.

Assim, a mesma mulher angolana que diariamente equilibra bacias na cabeça em busca do ganha pão, que já dialogou diretamente com o colonizador e que contribuiu para que muitos meninos não fossem mortos em guerra, viu-se sendo humilhada de diferentes formas, não sendo valorizada, honrada...

Já no período de guerra civil, as mulheres tiveram um papel importante para salvaguardar crianças, e até adultos nos momentos de intenso combate. Mesmo sendo tão vítimas quanto todos da população, assumiam estratégias em prol da sobrevivência daqueles que estavam em suas mãos. De acordo com Santos (2010, p. 48), no contexto de fome extrema, jardins no centro da cidade davam lugar a pequenas lavras:

Mesmo antes da Paz, as mulheres mostravam uma criatividade tão fértil quanto os seus campos de produção. Um povo tão rico quanto o seu país, em recursos minerais, não se sentou nem esperou de mãos cruzadas para ver seus filhos morrerem pela fome. Porque a mercadoria que o governo importava não chegava a todos os lugares de Angola. Também não dava para esperar as doações do PAM (programa alimentar mundial). Praças e jardins: Uma vez que os campos estavam minados, os jardins das cidades viraram lugares de cultivo para o milho, a batata, o tomate, a alface, a gimboa, a couve e outros legumes e verduras. Outros mais radicais levaram para a cidade suas criações de aves e alguns animais domésticos que estavam habituados a criar nos campos para ajudar na alimentação da casa. Isso ainda está ocorrendo atualmente em áreas onde a desminagem ainda não se efetivou. 
Mas mesmo com inúmeras estratégias para sobrevivência, a guerra não poupava a ninguém, e a terra, que antes fora meio de subsistência, tornava-se meio de aniquilação. De acordo com Souza (2017, p. 38):

As minas foram 'armas de guerra' de certo modo pensadas para atingir majoritariamente as mulheres, levando em consideração as lavras - onde foram colocadas -, espaços eminentemente domésticos e de sobrevivência familiar, em Angola trabalhados tradicionalmente por mulheres.

A guerra foi terrível com todos e, especialmente, com as mulheres. Se elas eram o elo necessário para a manutenção da vida familiar, precisavam ser as primeiras a serem banidas. Por isto mesmo as minas foram implantadas em seus espaços de trabalho, as lavras.

Esses aspectos todos reunidos conferem às mulheres angolanas uma grande importância quanto à trajetória do país o que, no entanto, não faz jus aos direitos a elas conferidos. Embora tenham sido e são essenciais na sociedade angolana, os seus direitos são negados, fazendo com que, contraditoriamente, vivam à margem da sociedade, sem o reconhecimento que merecem. Como afirma Domingos (2018, p. 16),

Desde o período da luta anticolonial que o papel da mulher angolana não tem sido suficientemente reconhecido. No contexto pós-independência, no âmbito das negociações do cessar-fogo da guerra civil angolana, o cenário manteve-se idêntico. As mulheres não foram chamadas a ser parte ativa do processo de mediação e negociação para pôr fim à guerra civil angolana. A exclusão das mulheres nos processos de paz é uma prática recorrente em África.

Embora a citação apresentada nos chame atenção para a não presença das mulheres nos acordos de paz, isso não exclui a participação não documentada. Afinal, as mulheres estavam vivendo intensamente os sofrimentos do povo, a perda sistemática de seus esposos, filhos e filhas. Cabe a elas, muitas vezes, lançarem mão de estratégias em prol da sobrevivência de crianças, adultos e delas mesmas.

No que tange à participação política documentada, Domingos (2018, p. 17) afirma que:

No contexto de paz militar, a inclusão e participação das mulheres não conheceu grandes melhorias. Sua presença e participação nos órgãos de decisão são ainda muito fracas. Por exemplo, em 2008 - 
seis anos depois de alcançada a paz militar -, dos 29 Ministros de Estado, as mulheres eram titulares de três pastas; dos 45 vice-ministros, apenas cinco mulheres. No parlamento, do total de 220 deputados, apenas 36 eram mulheres. Na governação local, entre os 18 governadores provinciais e os 37 vice-governadores, só uma mulher. Entre os 161 Administradores municipais, apenas três mulheres e entre os 347 administradores comunais, apenas cinco mulheres. No poder judiciário as mulheres ocupavam apenas $13,3 \%$ dos cargos.

Esses números comprovam o quão distante está a relação de equidade de gênero no cenário político social angolano, devendo trazer grande alarde na esfera social, visto que uma sociedade só tem um real crescimento quando é percebida a preocupação com representação de todos no contexto político. Todavia, no atual governo, observa-se o aumento considerável da presença feminina: para além de uma Ministra de Estado para área social, estão mulheres à frente dos seguintes Departamentos Ministeriais: Finanças; Ensino Superior; Ciência, Tecnologia e Inovação; Educação; Saúde; Indústria; Urbanismo; Ambiente; Ação Social, Família e Promoção da Mulher; Juventude e Desportos; Turismo; Cultura; e das Pescas e Mar. São onze em um universo de vinte e seis, cerca de $42,3 \%$.

São muitas as demandas evidenciadas que necessitam ser supridas: acesso ao sistema educacional, luta frente à violência doméstica, abusos, emancipação, e tantos outros que compõem um enorme emaranhado de dificuldades que impedem o desenvolvimento dessas mulheres.

As calamidades vividas pela mulher angolana não fazem jus ao seu papel, ante a sua contribuição para subsistência familiar, ante o papel sociopolítico. Muito se fala dos deveres, pouco se vê quanto aos direitos, e nessa ciranda nada harmônica, vemos mulheres sofrendo mais do que se alegrando, crescendo, vivendo, não sendo estimuladas nem mesmo para fazer algo simples, como estudar, direito elementar do ser humano.

Na próxima seção, discutimos como se dava a presença das mulheres no sistema educacional angolano, lançando mão de registros documentados por meio de fotos, para compreendermos as trajetórias de mulheres angolanas que conseguiram driblar as dificuldades e alcançar seus objetivos em meio a contextos de dúvidas e opressões. 


\section{MULHERES PARA LAVRA4, NÃO PARA AULA: realidades e falas entrecruzadas}

Iniciamos essa seção com o que foi o lema da sociedade angolana durante séculos e que só não é mais aplicado com tanta incidência porque o trabalho agrícola vem aos poucos sendo alocado em regiões cada vez mais afastadas dos grandes centros. No entanto, assumimos esse viés por acreditar que os discursos têm o poder de se entrelaçar e residir nas entrelinhas de novos discursos, produzindo interdiscursos. Assim sendo, por mais que não se use o termo lavra, ela, por si só, se transforma em novas incumbências tais como: fogão, criação de filhos, casa, marido, zunga e tantas outras ações. Ações distantes do sistema educacional, da vida profissional, da emancipação.

Embora se lute com possibilidades de representatividade na esfera política e governamental para cumprir acordo da SADC (Comunidade de Desenvolvimento da África Austral), que determina participação de $30 \%$ de mulheres nos órgãos de decisão, a essência da emancipação em Angola é um capítulo a ser discutido. Por enquanto, ela é uma miragem, na medida em que, para a sua concretização precisará de ações educativas e consistentes, começando pela organização social familiar, eliminar a distribuição preconceituosa das atividades domésticas, enfatizando a educação de todos na corresponsabilidade para a manutenção familiar, dentre outros.

Sobre emancipação, podemos dizer que o povo angolano se livrou do jugo opressor do colonizador, mas as mulheres por sua vez, permanecem vivendo opressões diárias, não sendo, assim, totalmente independentes como se esperava ainda no ano de 1975.

A presença de mulheres na educação no período colonial sempre foi muito baixa, na guerra civil houve um aumento, se comparada com a porcentagem dos homens, mas porque nesse tempo boa parte dos rapazes eram recrutados para guerra. Assim sendo, temos uma diferença que não

\footnotetext{
${ }^{4}$ Agricultura
} 
está relacionada com a valorização do gênero feminino, mas, sim, com as circunstâncias vividas naquele momento.

Para compreendermos melhor, podemos observar o quadro abaixo, que apresenta a relação de homens e mulheres, em escolas, no período colonial:

QUADRO 1 - Relação de Estudantes no Século XIX

\begin{tabular}{|c|c|c|}
\hline ANO & MENINOS & MENINAS \\
\hline 1846 & 177 & 21 \\
\hline 1847 & 295 & 25 \\
\hline 1848 & 390 & 18 \\
\hline 1849 & 439 & 8 \\
\hline 1850 & 317 & 7 \\
\hline 1851 & 341 & $X$ \\
\hline 1857 & 668 & 36 \\
\hline 1858 & 649 & 14 \\
\hline 1860 & 616 & 11 \\
\hline 1861 & 812 & 33 \\
\hline 1862 & 806 & 25 \\
\hline
\end{tabular}

Fonte: Frequência Escolar em Angola nos meados do século XIX (MARTINS, 1998, p.133).

O quadro apresentado nos faz refletir sobre a segregação de mulheres no cenário educacional, mas um fato tão importante quanto este é pensar sobre a quantidade de mulheres negras que ocupavam esse espaço.

Falar sobre a presença de mulheres na educação angolana não é traçar considerações que residam apenas na questão de gênero. Essa escrita perpassa pela cor e questões socioeconômicas profundas. E antes que nos deixemos levar pelas datas apresentadas, segue abaixo uma imagem que retrata a presença bem inferior de mulheres no sistema educacional do século XX: 
Figura 1: Refeitório da Escola de Regentes Agrários do Tchivinguiro. Século XX.

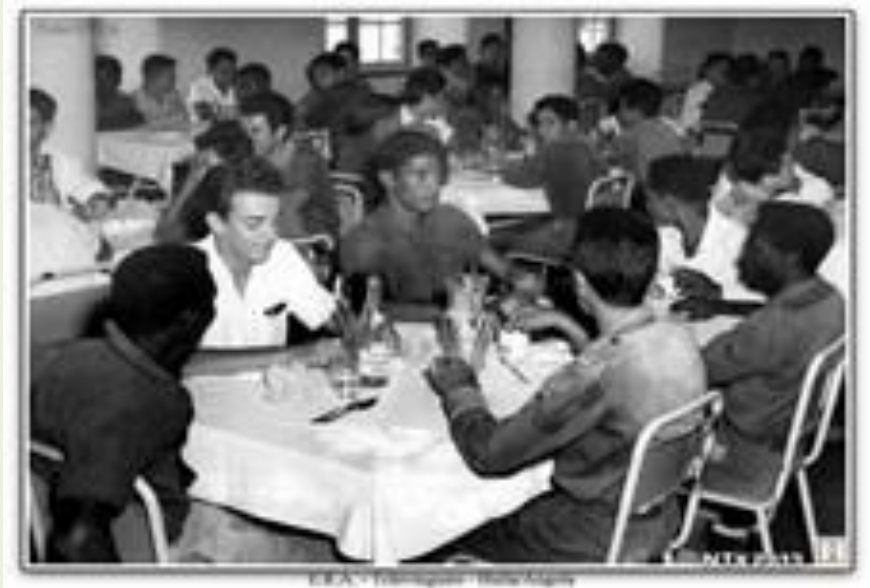

Fonte: Acervo obtido com professores pesquisados.

Se havia segregação entre os próprios homens quanto à cor, o que dizer quanto a mulheres e negras. A foto apresentada testemunha as ações "bem-sucedidas" do colonizador em diminuir, ao máximo possível, a presença de nativos no sistema educacional. De acordo com Dias (2013, p. 21):

Apesar da epistemologia feminista apresentar importantes contribuições para análise, a mesma peça, ao deixar intacta a discussão fundamental acerca da cor da epistemologia. A denúncia de que a ciência ocidental é masculina foi inicialmente feita pelas mulheres brancas dos centros universitários europeus e norteamericanos, que não colocaram em pauta a questão racial.

Em suma, podemos inferir que, no contexto angolano, ambas as discussões são valiosas para romper com séculos de opressões. Se as mulheres ocidentais brigavam pela presença delas nos ambientes acadêmicos e profissionais, as africanas brigavam duplamente por estes direitos. $\bigcirc$ que não pode fazer com que equiparemos as lutas, visto que elas residem em contextos opostos.

Ao realizar a entrevista com Nsona percebemos o que era prioridade entre os nativos no contexto angolano no período colonial, era o trabalho para garantir a subsistência pessoal e familiar. Ao mesmo tempo, vemos a discriminação feminina no prosseguimento dos estudos:

Eu repeti duas vezes a terceira classe porque o meu pai foi pedir para repetir. E eu não sabia porque. Era um período em que tinha 
que se mandar listas, para o estudante fazer o exame final, e eu sempre fui a melhor da sala, mas o meu nome não ia, o professor dizia: "esqueci do nome". Quer dizer, a pessoa é a melhor da sala e o nome não vai? No segundo ano o nome não vai novamente. Mas só depois é que o professor contou a verdade: "o teu pai pediu para não aprovares porque és pequena". No meu tempo, era terminar a quarta classe e arranjar um trabalho. Então, meu pai pensava: "mas essa vai terminar a quarta classe, assim tão pequenina e depois faz o que? Então é melhor ir repetindo e depois vai aumentando de idade para depois começar a trabalhar". Assim terminei com 13 anos a escola. Isso marcou-me muito, depois quando eu soube da verdade. Porque eu sempre gostei de estudar. Nós tínhamos uma distância de quilômetros, nunca cheguei tarde e antes de sair de casa minha mãe dizia antes de sair para ir para a escola tens que capinar essa distância. Eu madrugava. Pequena, madrugava para capinar a minha distância e carregava meus irmãos para irmos à escola. Isso marcou-me... (Nsona, entrev, 2016).

Na fala da professora Nsona, acima, podemos perceber as tradições do passado enraizadas na constituição da sociedade. Já era de se esperar que houvesse essa cobrança para que as mulheres assumissem as suas tarefas domésticas, ou outro trabalho, em algum lugar. A educação não era prioridade, verdadeiramente. Embora o pai não quisesse ter a filha trabalhando em qualquer lugar, a mãe fazia questão de que ela trabalhasse antes de ir à escola. Vemos o ingresso tardio das meninas nos níveis mais avançados. De um lado, segregação pela cor, de outro as pressões para que essas moças assumissem os seus papéis como domésticas. Isso é possível notar na foto a seguir, onde percebemos a quantidade reduzida de mulheres negras em sala.

Figura 2: Liceu Diogo Cão - 1960-1961

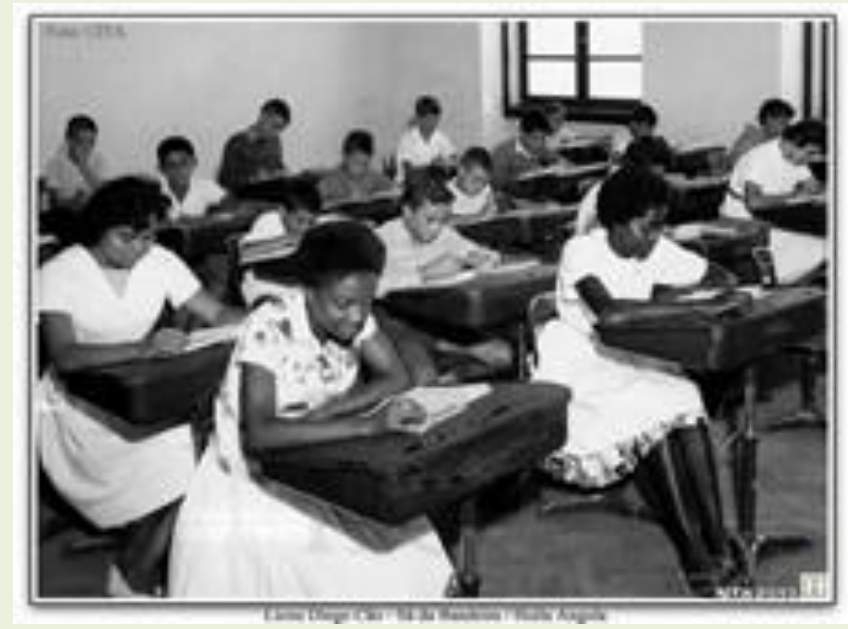

Fonte: Acervo dos professores pesquisados. 
Imagens como essas reforçam o depoimento feito pela professora. A oportunidade tardia para que as estudantes ingressassem em turmas avançadas fazia com que as poucas que alcançavam esses níveis terminassem com uma idade acima dos colegas homens. Onde estavam essas mulheres? Trabalhando.

A prioridade para os nativos não era o estudo e para mulheres muito menos. Quanto menos tivessem acesso a esses níveis, melhor seria, pois, assim, elas poderiam ater-se às tarefas domésticas e à subsistência do lar.

Com o fim da política colonial, Angola pôde experimentar algumas mudanças. Muitos homens e mulheres que a priori não poderiam estudar viram, na abertura de um novo tempo, a chance tão almejada de ingressar na escola. É o que relata Tchissola:

\begin{abstract}
Iniciei meus estudos primários em 1978. Três anos depois da independência, que foi em 1975. Naquela altura deu-se a abertura de toda a gente poder estudar. O estudo era gratuito, não se pagava nada. Nem o material escolar, então houve uma demanda muito grande de alunos para estudar. Eu tive a sorte de entrar também nesse ano, estudei numa escola, era escola muito pequenina. Tinha apenas quatro salas, Naquele sítio, havia uma escola, uma igreja e um cemitério. É um sítio onde viveram os primeiros colonos madeirenses, que chegaram aqui a Huila. E nessa escola é onde estudavam os antigos filhos dos colonos. Depois da independência, deu-se a abertura de toda a gente poder estudar. Então, eu entrei naquela escola. É um sítio histórico. Atualmente, é considerado um monumento histórico da Huila. E foi ali onde eu comecei os meus estudos primários.
\end{abstract}

Tchissola pôde experimentar uma chance ímpar negada a tantos negros e, especialmente, a mulheres negras num passado não tão distante. Como ela mesma expressa: "eu tive a sorte de entrar também nesse ano..." Sua visão poderia estar carregada de incredulidade, visto que a escola em que estudou era até então um espaço reservado a filhos de colonizadores. Assim sendo, havia um significado diferenciado para ela, que gerava certa incredulidade.

Entretanto, as portas que se abriram com a independência, mas, também, trouxeram novos obstáculos. A guerra civil emplacada anos depois deu às mulheres o triste fardo de serem protagonistas em momentos de 
grande terror. Quando ainda era criança, Tchissola presenciou o conflito armado em sala de aula mesmo. Ela relata que, ao final dos conflitos, regressou para casa amparada por outras crianças:

Eu estava no ensino primário nessa altura. Isso foi em 79, quando os sul africanos bombardearam a fábrica de madeiras da Huila [...] houve pânico, porque aquilo foi um estrondo muito grande. As paredes estremeceram. E toda a gente estava com medo, crianças a chorar de um lado e do outro. E as professoras tentavam acalmar, mas elas também estavam com medo. Via-se no rosto delas que elas também estavamem pânico. E, prontos, não havia como irmos para casa, e fomos nos juntando coleguinhas do mesmo bairro. E depois fomos todos em grupo, para casa. Sozinhos, não tinha adulto nenhum.

Nesse período, Tchissola era uma criança que via na educação uma oportunidade para dias melhores, mas que ainda não pudera experimentar dessa oportunidade com toda a sua completude, pois a sociedade mais uma vez rumava para o sentido contrário. Nesse período, o número de mulheres era maior nas escolas, o que não era um privilégio, mas uma consequência, visto que muitos rapazes eram capturados para lutar na guerra civil deflagrada logo após a independência de Angola.

Anos depois, já como profissional da educação Tchissola experimenta novamente os impactos da guerra. Ela relembra que:

Em 92, foi quando houve as primeiras eleições em Angola. Então, o partido político UNITA não aceitou [o resultado d] as eleições e partiu novamente para a guerra. Houve confrontos nas cidades, e a nossa não escapou. Muitas lojas foram saqueadas, tiroteios. E eu estava na escola, nessa altura já como professora, a dar aulas. Houve pânico de novo na escola, os meninos choravam de medo. Tentavam acalmar, mas prontos depois os pais pouco a pouco foram recolhendo os filhos. E eu acabei ficando sozinha ali na sala. Depois enchi-me também de coragem e fui. Era muito mais distante, porque eu vivia no bairro do Chioco e trabalhava aqui na cidade. Fiz o trajeto a pé. As pessoas tinham medo de ir para o trabalho. Medo de serem atingidos ali na rua por um tiro. Boa parte das pessoas ficou umas duas semanas sem trabalhar. Depois das forças do governo tomarem conta da situação, mais ou menos, é que as pessoas começaram a trabalhar.

O relato de Tchissola é um no meio de uma infinidade de outros relatos os quais se perderam com o tempo. Seu protagonismo como professora demonstra o quanto a mulher angolana é importante para a sociedade. 
Permanecer na escola até que cada um fosse levado para casa era um desafio. Regressar sozinha para casa em meio a diferentes ameaças após confronto armado era um desafio ainda maior, mas ainda assim ela não esmoreceu.

Esse relato de experiência de Tchissolanos leva às palavras de Freire (2011, p. 72), quando diz: "Os oprimidos nos vários momentos de sua libertação, precisam reconhecer-se como homens, na sua vocação oncológica e histórica de ser mais. A reflexão e a ação se impõem, quando se pretende, erroneamente, dicotomizar o conteúdo da forma histórica de ser do homem". É assim que Tchissola, até mesmo sem perceber, exerceu ações de persistência mesmo diante das adversidades. Nesse período, ela se dividia entre os estudos e o trabalho. O interessante é perceber que a fonte de renda que até então vinha por meio da agricultura agora passa a ser por meio da educação.

Naquela altura, eu já trabalhava, então eu fazia as duas coisas, estudavam [também]. Se estivesse a estudar de manhã, lecionava à tarde. Se estivesse a estudar à tarde, então lecionava de manhã. Não foi fácil, porque vivíamos muitas dificuldades, tínhamos que passar noites em claro preparando as aulas e preparar também os meus estudos. Havia muita dificuldade (Tchissola, 2016, entrev).

Enquanto isso Nsona buscava assumir as rédeas da sua vida, sem sucesso. Ao tentar estudar engenharia química se vê impossibilitada, desta vez não pelo gênero, mas pela cor:

Depois pedi transferência na faculdade de engenharia. Queria fazer engenharia química e fui transferida pelo reitor naquela altura. Mas não ingressei na engenharia química, por racismo. Eu não tenho problema em dizer que era por racismo, porque a engenharia química era para a elite branca. Era sim, era sim. Apesar de ter a transferência, não fui permitida a entrar na engenharia química. Fiz toda a luta e não consegui (Nsona, 2016, entrev).

Apesar de o episódio ocorrer no período de independência, ainda na década de 1970, as marcas permaneceram. Afinal não se apaga uma história de 400 anos de opressão do dia para a noite. Freire $(2011$, 62) afirma que:

Na análise da situação concreta, existencial, de opressão, não podemos deixar de surpreender o seu nascimento num ato de 
violência que é inaugurado, repetimos, pelos que têm poder. Esta violência, como um processo, passa de geração a geração de opressores, que se vão fazendo legatários dela e formando-se no seu clima geral. Este clima cria nos opressores uma consciência fortemente possessiva. Possessiva do mundo e dos homens. [...] Daí que tendam a transformar tudo o que os cerca em objetos dos de seu domínio. A terra, os bens, a produção, a criação dos homens, tudo se reduz a objeto de seu comando.

Diante disso, Nsona experimentou dessa possessividade que, a priori, poderia ter sido abafada pelos gritos de libertação, mas que ainda estava entranhada nos diferentes setores da sociedade. É importante reforçar que Nsona, de certa forma, não estava no "perfil" de alguém que poderia ingressar em um curso "nobre" como o de engenharia, ela era de origem pobre, filha de agricultores, mulher e negra. Mas não se deixou abalar e continuou a lutar pelo espaço que pretendia e continuou a estudar, até alcançar o seu diploma como professora de Matemática na primeira turma de Licenciatura do país.

A guerra civil perdurou 28 anos, mas finalmente chegou o cessar fogo. No entanto, as dificuldades não cessaram no país, muito menos na vida dos seus cidadãos. Quando quis realizaro mestrado, Nsona, mais uma vez, precisou perseverar.

Fui já fazendo as guerras internas na Faculdade onde trabalhava para que me autorizassem a fazer pelo menos o mestrado, porque precisava elevar o nível. Foi de fato uma guerra, até que fui autorizada, em 2001, a fazer o mestrado. Fazer o mestrado ou equivalente, e depois regressar, para começar a fazer o vai e vem. Mas eu fui para lá, fui com os meus 3 filhos, depois tive o quarto. E fiz naquela época, na Universidade de Madrid, chamava-se estudos avançados, que era o equivalente ao mestrado. Então, quando terminei, em princípio eu deveria regressar. Regressar e depois fazer o vai e vem, é claro que não poderia fazer o vai e vem com três filhos. Ingressei diretamente no doutoramento. Isso foi um problema sério na Faculdade, porque naquela época disseram que eu era indisciplinada, que eu fui para fazer o mestrado e estava fazendo o doutoramento, então fiquei dois anos sem subsídio, sem bolsa, sem nada. Diziam "Já que você decidiu, então, agora vira-te"). Mas depois, consegui um bilhete de passagem, e marquei uma audiência com o ministro da educação, pois era ele que autorizava naquela época as bolsas do INAGBE (Instituto Nacional de Gestão de Bolsas de Estudo) e pedi bolsa. Expliquei a minha situação. Já estava fazendo o doutoramento e autorizaram-me 2 anos só, infelizmente em dois anos também não terminei. Eu já fiquei 2 anos sem bolsa. Tive que buscar forma de trabalhar para poder sustentar os filhos, para poder viver lá. Também não podes conciliar isso com o trabalho 
de doutoramento. Fiquei dois anos, mas também não terminei pedi outra vez, fiz as cartas, o meu diretor fez uma informação a dizer como estávamos que eram necessários mais dois anos pra eu terminar. Deu me mais dois anos e terminei o doutoramento em 2010. Mas, nessa altura, ainda fui obrigada a fazer o vai e vem, comecei já a escrever a tese estava na iminência de me tirarem os salários, me tirar do sistema, porque [me disseram], ou fazes o vai e vem, vem pra cá dar aulas, ou rescindimos o contrato. E tive que deixar meus filhos aí com uma amiga, e sempre que estava de férias vinha para cá fazer o vai e vem. E, também, o objetivo era mudar de categoria, não mudei de categoria, depois de terminar o vai e vem. Como fica? "Ah não estamos autorizando os que estão no país". Pronto, então quando vim para o país foi quando me mudaram de categoria.

A busca pela educação dessas mulheres não se esgota no primeiro não, nem no segundo, elas perseveram, apesar do sistema tentar puxá-las para trás. E o sistema perde. A educação nunca foi uma prioridade no contexto angolano, a história que temos relatado nos mostra claramente isso. E quem perde é o país, que ano após ano se deixa levar pelas circunstâncias e não assume suas responsabilidades para com o povo.

Nsona e Tchissola são mulheres que contrariaram as estatísticas para escrever a sua própria história. Se no passado elas deveriam ajudar a sustentar as suas casas com trabalho agrícola, hoje elas sustentam por meio da educação. Mas não foi tarefa fácil, enfrentaram: segregação racial, segregação de gênero, guerra, instabilidade política, social. Elas contrariaram as estatísticas, portanto, são uma exceção. Santos (2010, p 46) relata que:

A maior parte das mulheres angolanas são encontradas nos mercados ou dentro das casas como empregadas domésticas ganhando o equivalente a US\$50. Outras são encontradas nas esquinas das ruas trocando dólar; outras, como vendedoras ambulantes, vendendo desde o peixe, frutas, legumes, aperitivos, roupas, brinquedos, água gelada nos saquinhos, aos mais diversos produtos; outras são encontradas sentadas em frente às suas casas debaixo de tendas esperando serem pagas, pois são as chamadas muamberas, descriminadas, mas que contribuem muito com seus produtos para a diversidade e o livre comércio, permitindo assim uma opção. São elas, na maioria, que asseguram a renda familiar. Custeiam os estudos dos filhos e mantêm seus maridos, muitos deles desempregados ou funcionários públicos que têm como salário básico o equivalente a quase 100 dólares, recebidos, na maior parte das vezes, com atraso de três a seis meses. Elas também são encontradas nos setores públicos, como funcionárias de empresas particulares e do governo, como professoras, engenheiras, médicas, enfermeiras e até ministras e deputadas, mas são minoria. O nível de 
analfabetismo da população angolana ainda está mais alto na camada feminina.

Embora o número de mulheres que estudam tenha aumentado ao longo dos últimos anos, ainda é possível notar que as mulheres ainda são vistas como inferiores, pois não têm os seus esforços devidamente valorizados. A história comprova a sua importância, mas as ações não. Assim, gerações de mulheres precisam lidar com a opressão em diferentes períodos da história, que não é combatida de modo efetivo pela sociedade angolana.

\section{CONSIDERAÇÕES FINAIS}

Por meio desta pesquisa, percebemos que a mulher é fundamental para a sociedade angolana, desde os primórdios da sua constituição, sendo elo necessário para que a dinâmica social funcione com qualidade. No entanto, pelos episódios de vida narrados, não há, na prática, valorização dessa importância. O que as professoras colaboradoras conseguiram alcançar, foi a custo de muito enfrentamento e superação pessoal de adversidades presentes no contexto social. Os resultados aqui encontrados são corroborados pela constatação da ínfima presença de mulheres no sistema educacional e, também, nas esferas de caráter decisório do país, dados discutidos neste artigo.

A ausência de uma presença mais efetiva de mulheres nesses níveis favorece o aumento da desigualdade social, tendo em vista que muitas dessas mulheres continuam exercendo a função de provedoras dos seus lares. Assim sendo, se não há qualidade de formação dessas mulheres, não obterão funções bem gratificadas e, consequentemente, não terão condições adequadas para a criação dos seus filhos, levando dessa forma o país a níveis cada vez maiores de pobreza.

Nsona e Tchissola nos levam a refletir sobre a importância da educação na formação do cidadão e o quanto políticas públicas não direcionadas para isso podem ser um grande obstáculo para a formação e o desenvolvimento profissional de mulheres nessa sociedade. Os resultados 
desta pesquisa possibilitam-nos recomendar que 0 processo de desenvolvimento social angolano olhe com atenção para as suas cidadãs, perceba o potencial que nelas existe para que possam exercer as suas profissões e papeis nessa sociedade com dignidade.

Para concluir, compreendemos que o país, com nome feminino, necessita olhar com mais sensibilidade para as mulheres que 0 ajudaram/ajudam a se reconstruir, crescer e fluir. Assim como no passado, as mulheres podem promover muitos benefícios para o avanço do país em suas diferentes áreas, basta que sejam, verdadeiramente, valorizadas, e isso começa com o incentivo, estímulo e apoio aos estudos.

Entendemos que este artigo, por meio das histórias de vida e formação profissional das colaboradoras, oferece contribuições para políticas públicas de Angola e de outros países em desenvolvimento, cujas autoridades resolvam olhar a educação de seu país como uma estratégia de desenvolvimento dos cidadãos e do país como um todo.

\section{REFERÊNCIAS}

CAREGNATO, L. Domínio colonial português em angola nos séculos XV e XVI. In: Anais do X Encontro Estadual de História. Santa Maria: Universidade Federal de Santa Maria, 2010. p. 1-9. Disponível em:

http://www.eeh2010.anpuhrs.org.br/resources/anais/9/1279060711_ARQUIVO_Artigo-ANPUH-RSCorrigidoerevisado.pdf. Acesso em: 10 out. 2019.

CAREGNATO, L. Em terras do Ngola e do Manikongo: descrição dos reinos do Kongo e Ndongo no século XV. In: Anais do XXVI Simpósio Nacional de História - ANPUH, 2011 , São Paulo. Disponível em: http://www.snh2011.anpuh.org/resources/anais/14/1300849331_ARQUIVO_Te xto-ANPUH-SP.pdf. Acesso em: 13 out. 2019.

DIAS, H. M. Vozes e escritas femininas em Angola: a luta pela sobrevivência e emancipação de mulheres (1961-2002). 2013. 127f. Dissertação (Mestrado em História Social) - Pontifícia Universidade Católica de São Paulo, São Paulo/SP, 2013.

DOMINGOS, W. C. Vozes de mulheres: género e cidadania em angola.

Revista Espacialidades [online], v. 13, n. 1, p. 1-31, 2018. Disponível em: https://cchla.ufrn.br/espacialidades/v13/2018-dossie07.pdf. Acesso em: 13 out. 2019. 
FREIRE, P. Pedagogia do Oprimido. 50 ed, Rio de Janeiro: Paz e Terra, 2011.

FONSECA, M. B. NzingaMbandi conquista Matamba: legitimidades e poder feminino na África Central. Século XVII. São Paulo, 2014. Disponível em: http://www.encontro2014.sp.anpuh.org/resources/anais/29/1406225439_ARQ UIVO_NzingaMbandiconquistaMatamba,anpuhsp.pdf. Acesso: 25 Set. 2019.

\section{GONÇALVES, T. V. O. Ensino de Ciências e matemática e formação de} professores: marcas da diferença. 2000. 275 p. Tese (Doutorado em Educação) - Universidade Estadual de Campinas. Faculdade de Educação, Campinas, SP. Disponível em:

http://repositorio.unicamp.br/jspui/handle/REPOSIP/253686. Acesso em: 08 fev. 2021.

MENEZES, S. Mamma Angola: Sociedade e Economia de um País Nascente. São Paulo: Editora da Universidade de São Paulo: FAPESP, 2000.

MORAES, R; GALIAZZI, M. C. Análise textual discursiva: processo reconstrutivo de múltiplas faces. Ciência e Educação, v. 12, n. 1, p. 117-128, 2006. DOl: http://dx.doi.org/10.1590/S1516-73132006000100009. Disponível em: https://www.scielo.br/pdf/ciedu/v12n1/08.pdf. Acesso em: 12 fev. 2021.

RENDINHA, J. Etnias e culturas de Angola. Lisboa: Associação das Universidades de Língua Portuguesa (AULP), 2009.

SANTOS, V. I. A situação da mulher angolana uma análise crítica feminista pós-guerra. Portal Metodista de Periódicos Científicos e Acadêmicos, v. 16, n. 16, p. 39-62, 2010. DOI:10.15603/2176-0985/mandragora.v16n 16p39-62. Disponível em: https://www.metodista.br/revistas/revistasims/index.php/MA/article/view/1998/2010. Acesso em: 13 out. 2019.

SOUZA, M. S. D. O corpo amoroso em o livro da paz da mulher angolana, as heroínas sem nome: subsídios para leitura. Revista do NEPA/UFF, v. 9, n.18, p. 29-44, 2017. DOI: 10.22409/abriluff.v9i18.29919. Disponível em: file:///C:/Users/Dr.\%20Alfredo\%20Buza/Downloads/DialnetOCorpoAmorosoEmOLivroDaPazDaMulherAngolanaAsHeroin-6054394.pdf. Acesso em: 10 out. 2019.

WEBER, P. NzingaMbandi: representações de poder e feminilidade na obra do padre Cavazzi de Montecúccolo. AEDOS, v. 3, n. 7, p.1-14, 2011. Disponível em: 16014-70822-1-PB.pdf. Acesso em: 10 out. 2019.

Recebido em: 10 de fevereiro de 2021 . Aprovado em: 11 de abril de 2021. Publicado em: 12 de abril de 2021. 